\title{
43. ACERCA DE POTENTILLA SUPINA L. EN LA PENÍNSULA IBÉRICA
}

\author{
Pedro SÁNCHEZ-GÓMEZ y Jaime GÜEMES
}

Palabras clave. Potentilla supina, Rosaceae, Península Ibérica, corología.

Key words. Potentilla supina, Rosaceae, Iberian Peninsule, chorolory.

Potentilla supina L. es una especie subcosmopolita de distribución original eurasiática y norteafricana (cf. Pesmen in P.H.Davis (ed.) Flora of Turkey 4: 46-47. 1972), de cuya presencia en la Península se tiene sospecha desde antiguo. (cf. Willkomm in Willkomm \& Lange, Prodr, Fl. Hispan. 3: 234. 1874), siendo confirmada por recolecciones posteriores de Almagro, dadas a conocer por Pau (Actas Soc. Esp. Hist. Nat. 27: 68. 1898) en la provincia de Teruel. Mateo (Catálogo florístico de la Provincia de Teruel: 328. 1990) confirma la presencia de la planta en la provincia con nuevas recolecciones en el $\mathrm{Va}$ lle del Jiloca.

A pesar de ello, como indica Mateo (op. cit.), esta especie no fue citada por Ball et al., (in Tutin et al. (Eds.) Flora Europaea 2: 42. 1968) en la Península Ibérica, aunque sí se presenta en paises próximos (Italia y Francia). También es conocida en África del Norte donde Maire (Fl. Afrique N. 15: 186. 1980) la cita en Marruecos, Túnez y Egipto, en bordes de lagos de montañas calcáreas.

Recientemente, Herrero-Borgoñón y Crespo (Acta Bot. Malacitana 17: 256-258) citan esta especie en la ciudad de Valencia, considerándola una planta introducida junto a otras especies, ornamentales o cultivadas, en los céspedes de los jardines de la ciudad. En el mismo trabajo, como consecuencia de la revisión del herbario MA, se anotan otras localidades ibéricas de las provincias de Ciudad Real, Guadalajara y Teruel. Sin embargo, consideramos que la localidad atribuida a Ciudad Real (Lagunas de Ruidera, La Redondilla) pertene- ce a la provincia de Albacete al igual que otra cita de Laguna Concejo dada por Velayos (Contribución al estudio de la flora y de la vegetación de las Lagunas de Ruidera y su entorno: 114. 1983), muy cerca del límite de provincia con la de Ciudad Real, lo que hace sin duda probable su presencia en dicha provincia.

Por nuestra parte hemos recolectado Potentilla supina en la cuenca del Segura y a las citas ya indicadas hay que añadir la que sigue: ALBACETE: Socovos, Márgenes del Embalse del Cenajo, 30SWH9948, 400 m, 20VII-1991, P. Sánchez-Gómez y J. Güemes. MUB 37684. A lo largo de los márgenes del Embalse del Cenajo, existen numerosas poblaciones entre las que hemos detectado, aunque no recolectado, algunas adentradas en la provincia de Murcia en el término municipal de Moratalla (30SXH04). La planta ha sido encontrada en pastizales frecuentados por el ganado implantados sobre arenas y limos hipernitrificados y temporalmente inundados, ecología muy similar a la de las localidades ya conocidas de márgenes de embalses. Los ejemplares florecen abundantemente y producen numerosas semillas, su expansión es posible, pero siempre estará limitada a zonas con abundante humedad edáfica y altamente nitrificadas. Las plantas acompañantes más frecuentes son Chenopodium ambrosioides L., Xhantium strumariun L. subsp. cavanillesii (Schouw) D. Löve \& Dansereau, Verbena supina L., Euphorbia nutans Lag., Eclipta prostrata (L.) L., Amaranthus blitoides S. Watson, Amaranthus albus L., etc., casi todas ellas alóctonas de origen americano. 
Como consecuencia de la revisión del herbario MAF, hemos detectado pliegos duplicados de las localidades de Ruidera y Entrepeñas que recogen Herrero-Borgoñón y Crespo (op. cit.), así como una recolección de la provincia de Cuenca: CUENCA: Laguna del Rocho, 13-VII-1966, Rivas-Goday y Borja. MAF 76007. Este pliego serviría como testimonio de la localidad que Willkomm (op. cit.) recoge de Quer y que, hasta el momento, no había sido confirmada.

Asimismo, en el herbario VAB se presenta un pliego que amplía el área de esta especie en la provincia de Guadalajara: GUADALAJARA: Alocén, Embalse de Entrepeñas, bajo el puente, 30TWK2394, 750 m. G. Mateo. VAB 922272.

De este modo se van añadiendo nuevas localidades a la antigua de Teruel, que van ampliando el área de distribución en la Península Ibérica de Potentilla supina, conociéndo- se poblaciones en las provincias de Albacete, Cuenca, Guadalajara, Teruel, Valencia, Murcia y muy posiblemente en Ciudad Real (fig. 1), en todos los casos ligadas a lagunas calcáreas y embalsamientos de agua frecuentados por el ganado o con una nitrificación grande y siempre en compañía de numerosas especies introducidas, lo que nos hace pensar en un origen semejante para la especie citada, que pudiera haber llegado por vía americana, donde se encuentra ampliamente naturalizada (Pesmem, op. cit.).

Aceptado para su publicación en Mayo de 1994

Dirección de los autores. P. SÁNCHEZ-GÓMEZ: Dpto. Biología Vegetal (Botánica). Facultad de Biología. Universidad de Murcia. 30100 Campus de Espinardo (Murcia). J. GÜEMES: Jardín Botánico de Valencia, Beato Gaspar Bono s/n. 46008 Valencia.

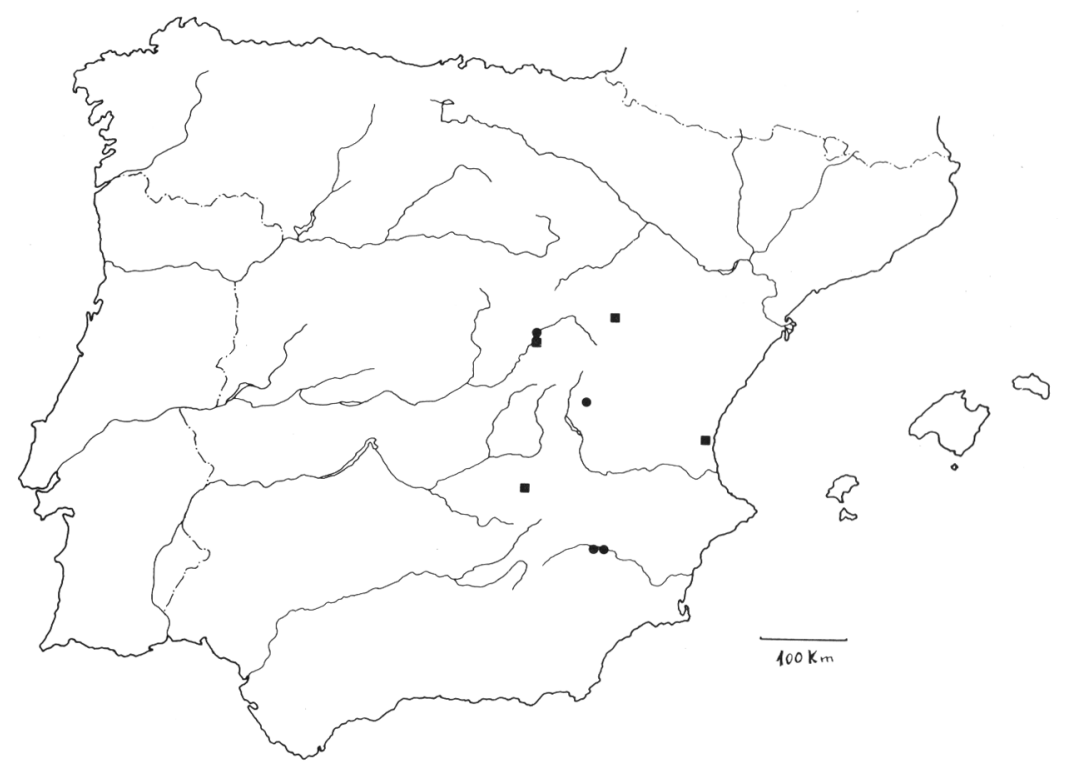

Figura 1. Distribución de Potentilla supina en la Península Ibérica. () localidades citadas por HerreroBorgoñon \& Crespo (1993); (•) nuevas localidades. En cuadriculas UTM 10 x $10 \mathrm{~km}$. Distribution of Potentilla supina in the Iberian Peninsule ( $\square$ ) localities cited by Borgoñón \& Crespo (1993); (•) new records UTM grille $10 \times 10 \mathrm{Km}$. 